\title{
Learning styles and perceptions of student teachers of computer-supported collaborative learning strategy using wikis
}

\author{
Kai Ming Li \\ Hong Kong Institute of Education
}

\begin{abstract}
This paper reports the results of an attempt to integrate a collaborative technology, Wiki, into learning within a course in a teacher education programme based on social constructivist learning theory. The current study aimed to explore student-teacher acceptance of the proposed pedagogy and to identify specific learning style preferences that might be favourable to accepting the proposed pedagogy. A total of 56 student teachers participated in this study. They completed a number of collaborative tasks using a wiki during the learning process, and were then invited to complete a questionnaire designed to solicit their perception on the usefulness of wikis and their attitudes towards using a wiki, and 39 of them also returned a learning styles inventory which was used to identify the learning styles profile of the student-teacher samples. The findings reveal favourable perceptions of the use of a wiki as a collaborative learning tool in the course. Qualitative data collected from open-ended questions also reflects similar favourable results. Active learners were also found to be significantly different from reflective learners in accepting the wiki as a learning tool.
\end{abstract}

\section{Introduction}

Proponents of the social constructivist view of learning consider learning a social activity rather than an egocentric task (e.g., Steffe \& Gale, 1995). They affirm that knowledge and understanding are constructed socially through conversation with others and through activities about shared problems and tasks (Bruner, 1966). Studies have also shown that a collaborative approach to learning can facilitate such social interaction processes, and that it is associated with greater understanding of a subject, increased productivity, higher motivation, and enhanced communication and problem-solving skills (e.g., Warschauer, 1997). Students in such a social environment can share their knowledge and discuss and construct meaning as a group via social interactions in assigned collaborative activities. Hence, the people and the culture surrounding individual students, as well as the learning design, significantly influence the meaning-making process (Doolittle \& Hicks, 2003).

The advance of Internet technology provides favourable tools for performing collaborative work. Students can share, negotiate, and discuss among themselves asynchronously after class in addition to face-to-face conversations in the traditional classroom setting. Students can also access a wide variety of online information and resources (Bonk \& Cunningham, 1998). Such tools are called cultural artefacts (Salomon \& Perkins, 1998) and may be in physical or digital form, such as books, videos, or web pages. They may also include technological tools or systems used for creating collaborative environments that support social interaction and content creation among group members (Augar, Raitman, \& Zhou, 2004). Hence, various computer-supported collaborative learning (CSCL) strategies and systems underpinned by the social constructivist paradigm have been developed, and many have been proven to enhance learning effectively (Koschmann, 1996; Koschmann, Hall, \& Miyake, 2002). Furthermore, the recent emergence of Web 2.0 also makes collaborative technologies, such as Wikis, more accessible to ordinary users, such as teachers and students. Wikis have been described as the easiest and most effective web-based collaboration tool (Educause, 2005), and their use has attracted the attention of many educators and researchers. For example, Parker and Chao (2007) positively commented on wiki as a platform for students to create a glossary, co-author an article, or work collaboratively on a project report. Wikis also have a positive impact on knowledge construction in a collaborative project. They facilitate the management of created content and discussions among students during project development at different places and times (Asterhan \& Schwarz, 2010; Engstrom \& Jewett, 2005; Kimmerle, Moskaliuk, \& Cress, 2009; Larusson \& Alterman, 2009; Mattison, 2003).

Although technological tools or systems may have a positive influence on learning, many empirical studies have found that some factors may influence the intention to use these technologies, which then 
affect the effectiveness of learning. These factors may include the users' perception of a particular technology, such as their perceived ease of use and usefulness, as well as their attitudes towards using it (e.g., Choi, Park, \& Park, 2012; Davis, 1989). They also include some external factors, such as the users' self-efficacy regarding its use, and system characteristics, such as functionality, accessibility, and technical support (e.g., Davis, 1993; Pituch \& Lee, 2006; Teo, 2011). Other than the above factors, learning style preference in terms of using a particular technology is also critical for the success of technology-based learning (Liegle \& Janicki, 2006). For example, Beadles and Lowery (2004) found that particular learning styles correlate significantly with academic achievement in an online learning environment, and that only students who possess particular learning styles can benefit from online learning.

Concluding from the above studies, wikis may be argued to be a promising technological innovation for collaborative learning. In a wiki, users can perform a variety of collaborative tasks or activities by accessing organised digital resources and guidance, as well as creating content together with other users on a common wiki page and soliciting or expressing opinions in such virtual environments apart from the traditional face-to-face communication in class. We may also predict that a number of factors affect the intention to use wikis. However, many of the studies discussed above adopted a quantitative approach and validated their proposed factors using a well-developed model, such as the technology acceptance model (Davis, 1989). Few scholars have attempted to solicit qualitative data to obtain in-depth understanding of the users' concerns and thoughts on the technology being used. Moreover, few scholars have focused on the effect of learning style preferences on the acceptance of using a web-based collaborative environment. Hence, the purpose of this study is to fill this gap by identifying the specific learning style preference(s) that may be favourable to the collaborative learning strategy supported by the use of wikis. This study also explores the concerns and thoughts on the implementation of this new pedagogy among a group of student teachers in a teacher education programme in Hong Kong. The results of this study will provide useful information for instructors regarding grouping and planning appropriate activities for students with different learning styles when collaborative technology is adopted. Three central research questions are addressed in this paper:

- Q1: What are the perceptions of student teachers regarding the use of wikis for collaborative learning?

- $\quad$ Q2: What is/are the learning style preference(s) of student teachers that may be favourable to using wikis for collaborative learning?

- Q3: What are the concerns and thoughts of student teachers on the implementation of this new pedagogy that uses wikis for collaborative learning?

The following sections begin with a summary of the key concepts from the related literature followed by the construction of the theoretical framework for this study. Research methods and the answers to the research questions are then presented. Finally, the paper concludes with a discussion of the major findings and their implications, as well as the limitations of this study that can be addressed by future studies.

\section{Literature review}

This section begins with a brief review on collaborative learning and its underpinning theory, social constructivism. The application of technology-based collaborative learning, such as CSCL and wikis, is then summarized. Arguments on the effect of learning styles on learning are reviewed along with the relevant psychometric instruments used to assess the learning styles of our student-teacher samples. Finally, a theoretical framework of this study is presented.

\section{Social constructivist theory and collaborative learning}

Social constructivist theory was derived from one of the major learning theories, constructivism, which suggests that knowledge is not passively transmitted from one end to another. Rather, knowledge is constructed when learners engage in meaning-making processes (Driscoll, 2000; Jonassen, Davidson, Collins, Campbell, \& Haag, 1995; Vrasidas, 2000). As indicated by the term social constructivist theory, the social element is added onto constructivism theory by emphasising social interaction in the learning process. Social constructivists assert that learners acquire knowledge mainly by participating in social interaction, especially in a learning environment. In such environments, learners can benefit from the 
interaction with a "more knowledgeable other" (MKO) (Vygotsky, 1978) because they may be unable to understand abstract concepts and ideas on their own (Woo \& Reeves, 2007). Hence, social exchanges among individuals are seen as the primary source of cognitive growth. Salomon and Perkins (1998) described such a learning process as "social scaffolding" (p. 9), in which learning occurs as a result of active social mediation when an individual is helped by an MKO. This MKO may be a teacher, a peer, or a group of peers, and they are considered to be a facilitating agent in the process of constructing personal meaning. In this study, the MKO can be any student teacher in a collaborative group or the instructor monitoring the learning progress in a collaborative activity. Salomon and Perkins (1998) argued that cultural artefacts, which may be in the form of information sources, such as books, videos, articles, or computer tools like wikis in this study, could also facilitate learning processes. Such a process is described as "cultural scaffolding" (p.5).

The concept of the MKO comes from Vygotsky's (1978) notion of the zone of proximal development (ZPD). Vygotsky (1978) defined ZPD as "the distance between the actual development level as determined by independent problem solving and the level of potential development as determined through problem solving under adult guidance or in collaboration with more capable peers” (p. 86). Thus, ZPD is the difference between the difficulty levels of a problem a learner can cope with independently, and the level that a learner can cope with accompanied by an adult (MKO) or a cultural artefact. The more a learner takes advantage of the MKO or cultural artefact, the wider the ZPD in the learning context. Once the learner masters assigned tasks, the MKO or cultural artefact, that is, the scaffold, can be removed, and the learner will then be able to complete the task again independently.

Moreover, social interaction can evidently be elicited when learners participate in collaborative projects, group assignments, or social events during conversation, discussion, and negotiation, which can enhance learning (Palincsar, 1998). Duren and Cherrington (1992) pointed out that the dialogical process in group activities can enhance individual communication and problem-solving skills. Following the ZPD concept, Vygotsky (1987) also argued that collaboration helps the learning process: "What the child [learner] is able to do in collaboration today he will be able to do independently tomorrow" (p. 211). Hence, collaborative learning is said to be an effective pedagogy and has been adopted in most learning scenarios.

Cooperative learning is also a common approach to learning and is sometimes interchangeable with collaborative learning because both involve small-group activities in which students take an active role in their learning process. Cooperative learning can bring about greater understanding, increased productivity, higher motivation, and a better sense of competence (Johnson \& Johnson, 1989; Rysavy \& Sales, 1991; Slavin, 1995). The following section gives a brief description of these two learning approaches and the distinction between them.

Collaborative learning is defined as the learning process in which two or more students are involved in a learning activity to create meaning, explore a topic or issue, or improve skills (Harasim, Hiltz, Teles, \& Turoff, 1995). The dialogical nature of a collaborative group provides an environment of social exchange in which cognition can be shared (Bruffee, 1995). When members come into a collaborative group with different ZPD, they may have the chance to act as an MKO to assist the learning of others for particular tasks, according to their level of expertise. Thus, new concepts are presented and shared, and misconceptions are challenged and clarified as a result of such social exchange processes (Pontecorvo, 1993; Slavin, 1995). The active engagement of students in collaborative learning tasks is believed to facilitate the meaning-making process of students (Jonassen, 1994), develop their personal skills, such as thinking and reasoning (Bruner, 1966), create a knowledge-building community (Hewitt, 2002), and allow the notion of social constructivist theory to be put into practice (Kirschner, Martens, \& Strijbos, 2004).

In addition to the cognitive and social aspects described above, cooperative learning is informed by social interdependence theory (Johnson \& Johnson, 1989). This theory emphasises individual accountability within a group. Each student can achieve his/her learning goals only if all the other members achieve theirs. Cooperative learning, therefore, exists only when all the members in the group work together to accomplish shared goals (Johnson \& Johnson, 1989; Slavin, 1995). Moreover, the group should be structured and managed by an instructor to ensure the active participation of each member (Cohen, 1994). Johnson and Johnson (1989) identified some basic elements that are important components for all 
effective cooperative groups: positive interdependence, face-to-face interaction, individual and group accountability, appropriate use of social skills, and group processing, not all of which are found in most collaborative learning activities.

In this study, a collaborative approach was adopted. Clear objectives and requirements were given. The student-teacher participants were guided to complete a number of collaborative tasks and were expected to show their interactions and productivity in a wiki environment.

\section{Computer-supported collaborative learning (CSCL)}

CSCL is a way to support collaborative learning by using computers and the Internet. Its emergence can be traced back to the early 1990s when the Internet started changing human lives in many aspects. With its ubiquity, the Internet enables different users in different geographic locations to learn and work collaboratively with only a computer and an Internet connection at any time favourable to them. Hence, a number of projects aiming to develop a computer system for facilitating various collaborative learning pedagogies have been explored. One of the leading examples is the Computer Supported Intentional Learning Environment (CSILE) project. CSILE, later known as Knowledge Forum, was developed with the belief that knowledge generated by students through individual and group effort can enhance students' motivation and thus the intention to learn autonomously. In CSILE, students can create notes on a specific topic in text or graphical forms in a private space (an individual portfolio) and choose to make it public. Students can then collate the relevant notes generated by other students, annotate them, and add reference links to produce a common or master note in a public portfolio. An empirical study assessing the standardised achievement of students in language and mathematics shows a significantly higher score for CSILE groups than the control class in the knowledge-building construct of the instrument. CSILE groups also performed better in responding to the question, "What have learned from doing this unit?" by providing more in-depth explanations (Scardamalia, Bereiter, \& Lamon, 1994, p. 214). The project also revealed that CSILE students could construct more advanced diagrams to explain a concept with more details and illustrate causal relationships.

Many CSCL studies show that the user-friendliness and key functions of a CSCL system can help promote peer interaction and encourage groups of learners to share and contribute knowledge and expertise with other learners, as well as bring learners together to perform different collaborative tasks and intellectual exploration (e.g., Lipponen, 2002; Stahl, Koschmann, \& Suthers, 2006). Some even argue that CSCL is a student-centred tool because it grants students authority and control over their own learning progress by enabling them to participate actively in building their foundational knowledge (e.g., Hoppe, Ogata, \& Soller, 2007; Onrubia \& Engel, 2009). CSCL is also a scaffold that facilitates the intellectual transaction of students with their peers. With these social constructivist features, students obtain a better understanding of a concept or grasp the answers to questions more effectively (Lu, Lajoie, \& Wiseman, 2010).

\section{Wikis as environments for supporting collaborative learning}

The advance of Web 2.0 technology has made the wiki a collaborative tool that is convenient to access and easy to use. Goodnoe (2005) has described a wiki as "(a virtual space) designed to facilitate exchange of information within and between teams" (p. 56). Wikis are easy to operate. With minimal technology skills and cognitive load, users can read, create, reorganise, and update the content of a web page using a web browser, which easily allows them to concentrate on collaborative activities. Users can also see results of their collaborative effort or revert to a previous version of such result through the Edit History function (Augar, Raitman, \& Zhou, 2004; Larusson \& Alterman, 2009). With these fully editable features, teachers can support collaborative learning activities by preparing and structuring learning materials and guides on collaborative tasks. Students can create content on a common web page together, share digital resources, express ideas, and clarify questions via the communication tool. Hence, a wiki (Google Sites) was adopted as a CSCL system in this study because it is a simple tool for collaborative learning.

\section{Learning styles and learning}

Researchers have strived to formulate a variety of learning styles to understand the different learning preferences of students, which in turn help improve learning outcomes. Learning style has diverse 
definitions. For examples, Keefe (1979) defined learning style as the combination of cognitive, affective, and physiological characteristics specific to a learner when interacting with the learning environment. Jensen (2003) described it as a preferred way of thinking, processing, and understanding information. Different learning style theorists have also developed different learning style classifications or models. Coffield, Mosely, Hall, and Ecclestone (2004), in their meta-analysis on 71 learning style models and instruments, grouped learning styles into five families: constitutionally based learning styles and preferences, cognitive structure, stable personality type, flexibly stable learning preferences, and learning approaches and strategies. They also reviewed 13 influential models in the literature. For example, in Dunn and Dunn's (1993) model, the perceptual strength of individual learners makes them more prone to information presented visually, auditorily, tactually, or kinesthetically. Similarly, Thomson and Diem (1994) suggested four types of learners: auditory, visual, tactical, and kinesthetic learners. Moreover, Kolb (1984) developed the experiential learning model, which consists of two dimensions: concrete experience or abstract conceptualization, and active experimentation or reflective observation. These two dimensions lead to a combination of four types of learners: divergers, assimilators, convergers, and accommodators. Built on the design of most models as stated above, Felder and Silverman (1988) developed their first learning style model, which was further refined by Felder (1993). The model classifies learning styles into four dimensions, as (1) active-reflective: showing how students prefer to process information; (2) sensing-intuitive: looking into the type of information that students perceive intentionally; (3) visual-verbal: revealing the most effective sensory channel through which information is perceived; and (4) sequential-global: showing how students progress towards a learning task. Brief descriptions of the dimensions are listed below:

(1) Active learner (ACT) learns by trying things out and enjoys working in groups while Reflective learner (REF) learns by thinking things through alone or with a single familiar partner;

(2) Sensing learner (SEN) is a concrete thinker who prefers practical task which is oriented toward facts and procedures whereas Intuitive learner (INT) is an abstract thinker who like innovative task which is oriented towards theories and underlying meanings;

(3) Visual learner (VIS) prefers visual representations of presented material such as pictures, diagrams, and flow charts while Verbal learner (VEB) prefers written and spoken explanations;

(4) Sequential learner (SEQ) intends to learn in a linear thinking process which is divided into small incremental steps whereas Global learner (GLO) likes holistic thinking process and learns in large leaps (Felder \& Spurlin, 2005, p. 103).

This model has been widely applied in many studies on e-learning systems because it provides a framework for designing tasks or structuring content according to the profile of the learner. In addition, accompanied with the use of its validated and easy-to-use instrument Felder and Soloman's (n.d.) index of learning styles (ILS), the learning style preferences of individual users can also be identified easily (Felder \& Spurlin, 2005; Zywno, 2003). In this study, the ILS was adopted to detect the learning style profiles of the student-teacher participants.

Some studies have found that a large discrepancy between the students' learning style and the teacher's pedagogy makes a lesson boring and the students less attentive, which results in poor course performance (Felder \& Silverman, 1988; Felder \& Spurlin, 2005). Felder and Brent (2005) also showed that intuitive, verbal, reflective, and sequential learners outperform students with other learning styles in courses mainly taught by lecturing. Hence, a teaching practice that addresses diverse learning preferences would enhance the learning process of students (Dede, 2005; Zywno, 2002). Moreover, students can also learn more effectively in ways that match their learning style (Felder \& Soloman, 2008). Despite the positive effect stated above, Coffield et al. (2004) concluded in their meta-analysis that the pedagogical impact of learning styles remains controversial, and studies often have inconsistent findings. Hattie (2009), in his meta-analysis of the different influences on student achievement, also revealed that student characteristics alone, such as learning styles, only have a very mild effect on learning outcomes. He ranked all the identified factors by calculating their effect size (ES) and claimed that a conducive factor should have an ES greater than 0.4. Some of the most influential factors in the study by Hattie were related to student-centred pedagogies underpinned by social constructivist theory. For example, cooperative learning, peer influences, peer tutoring, time on task, and feedback have ES values ranging from 0.41 to 0.73. The effect of a wiki is unknown because related studies were not included in Hattie's analysis. However, by examining the features of a wiki as stated above, we may assume the positive effect of wikis on learning because the aforesaid pedagogies can be implemented in this collaborative environment. 
Hence, the effect of learning style preferences on the intentional use of wikis can be examined; this kind of research is still rare in the literature.

\section{Theoretical framework}

Informed by the studies discussed above, a wiki learning environment was designed. The collaborative learning process was supported by the provision of learning resources and guides as well as the content creation and communication tools in the wiki. The effect on learning in this environment is argued to be related to the intention of students to take part in it. Such intention may also be affected by the learning style preferences of the students, their perceptions of wikis, and the system characteristics of this technology. Given our belief that wikis are easy to use, the factors related to their characteristics and operations were not included in the questionnaire survey.

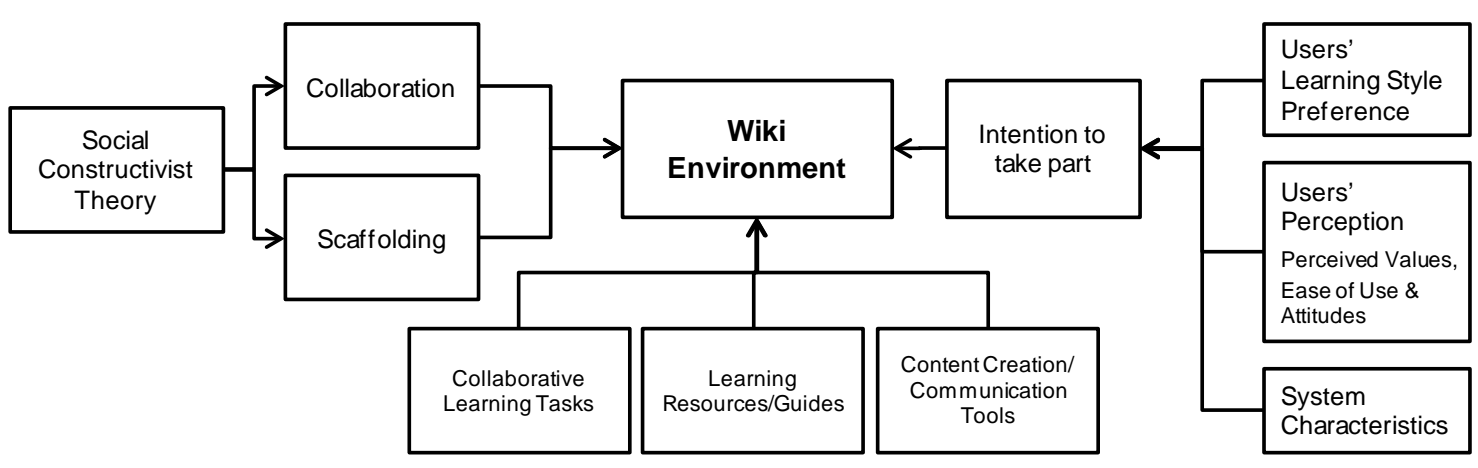

Figure 1. Theoretical framework of this study

\section{Method}

The following sections describe the participants, pedagogy, data collection, and analysis methods used in this study.

\section{Participants}

The participants were chosen using convenience sampling methods. They were students studying a General Education (GE) course, The Phenomenon of Internet and Digital Cultures (PIDC), in a teacher education institute in Hong Kong. PIDC is one of the elective courses for students from all levels and different programmes of the institute. Participation in this study was voluntary. A total of 56 student teachers (10 males and 46 females) completed a questionnaire (see Table 3 \& 4), and 39 of them (6 male and 33 female) submitted the Felder and Soloman's index of learning styles as well.

\section{The pedagogy in this study}

PIDC was conducted in a computer laboratory for 13 weeks. The pedagogy included lectures, a workshop, web-based collaborative activities and presentations. The first hour of the three-hour session was usually reserved for a lecture on a specified theme. The main purpose of this lecture was to provide different arguments on the theme from different information sources, which served as the backdrop for the subsequent collaborative tasks in the second part of the session. 

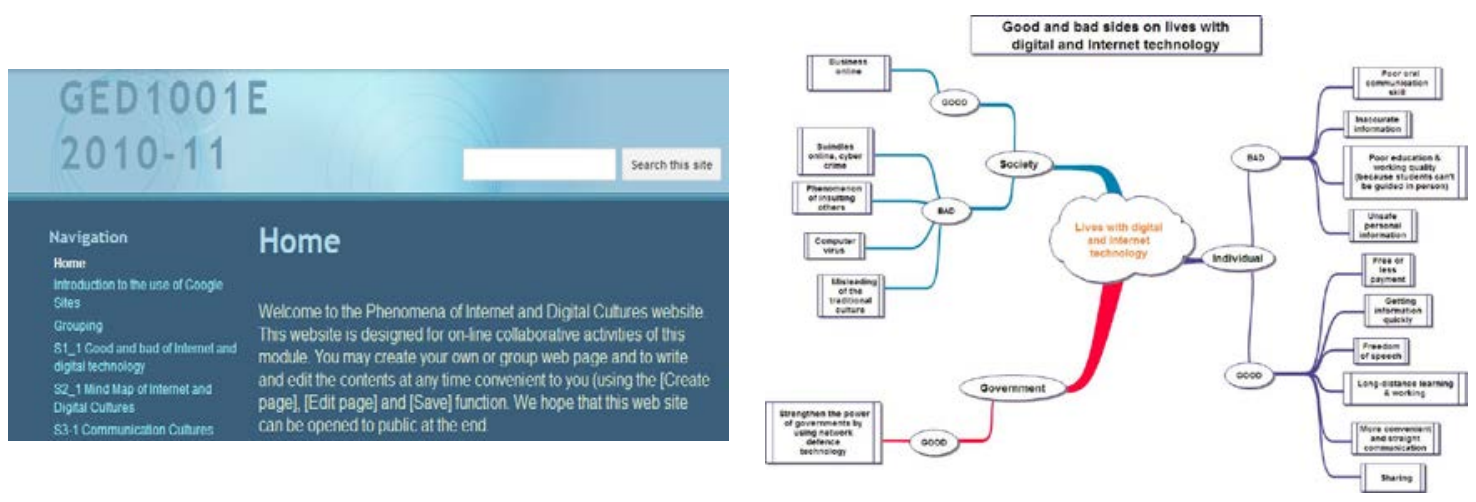

Figure 2. The wiki website of this study

Along with the face-to-face interactions in the class, students can use the navigation bar of a wiki site to access various instructions or resources and work on the collaborative tasks (as shown in Figure 2). The tasks in this study comprised different forms, such as discussing an issue or a question, debating online, and creating a group page for presentation. The outcomes of the group tasks were shared. Sharing was sometimes conducted online after class. A special task that involved the development of a database regarding knowledge about the latest Internet and digital technologies and a group presentation on the emergence of a culture and its impact on human life from the use of a specific technology was also included. To help the students create their artefacts in a web page using Google Sites, relevant video clips (YouTube videos) were embedded in the wiki, and a workshop on mastering these skills was conducted in one of the sessions (Table 1 presents examples on the themes and collaborative tasks). 
Table 1

Themes and collaborative tasks of selected sessions in the PIDC website*

\begin{tabular}{|c|c|}
\hline $\begin{array}{l}\text { Theme of a } \\
\text { session }\end{array}$ & Task \\
\hline $\begin{array}{l}\text { S1 Good and bad } \\
\text { of Internet and } \\
\text { digital technology }\end{array}$ & $\begin{array}{l}\text { Create your group page and write down the main points on the rationale behind these } \\
\text { statements: } \\
\text { (1) '... using... the Internet gives us more flexibility about where we go and how we control } \\
\text { our time, but at the same time, many people report that they feel more stress in their lives, } \\
\text { rather than less' (p. 2) } \\
\text { (2) 'There is no surprise that many people claim that the more we have access to } \\
\text { communication technologies, the less we really communicate.' (p. 3) } \\
\text { Go to the page of the other groups, and give your comments. }\end{array}$ \\
\hline $\begin{array}{l}\text { S2 Mind Map of } \\
\text { Internet and } \\
\text { Digital Cultures } \\
\end{array}$ & $\begin{array}{l}\text { Construct a mind map using 'Lives with Digital and Internet Technology' as the key theme in } \\
\text { Freemind, and upload the file using your group name here in JPG format. }\end{array}$ \\
\hline $\begin{array}{l}\text { S4 Video Game } \\
\text { Violence Debate }\end{array}$ & $\begin{array}{l}\text { 'Every time a child plays an interactive point-and-shoot video game, he is learning the exact } \\
\text { same conditioned reflex and motor skills'... ‘...he reflexively pulled the trigger, shooting } \\
\text { accurately just like all those times he played video games. This process is extraordinarily } \\
\text { powerful and frightening. ... our children are learning to kill and learning to like it.' (Grossman, } \\
\text { 2000, n.p.) } \\
\text { Source: Grossman, D. (2000). Teaching kids to kill. Phi Kappa Phi 'National Forum.' Retrieved } \\
\text { on } 1 \text { September } 2009 \text { from http://www.killology.org/article_teachkid.htm } \\
\text { Do you agree with the statement 'Our children are learning to kill and learning to like it' and } \\
\text { that parents and teachers need to stop our children from playing video games? } \\
\text { Assuming that your group will take one of the following roles, please provide evidence to } \\
\text { support the arguments of your group: } \\
\text { (1) Vendor - Against [Group 3]; (2) Parents - Against [Group 4]; (3) Parents - For [Group 1]; } \\
\text { (4) Teachers - Against [Group 2]; and (5) Teachers - For [Group 5] } \\
\text { Please also comment on arguments of other groups and respond to comments from other groups. }\end{array}$ \\
\hline $\begin{array}{l}\text { S6 Internet and } \\
\text { Digital } \\
\text { Technologies for } \\
\text { 21st Century } \\
\text { Learning }\end{array}$ & $\begin{array}{l}\text { Referring to the following assigned web technologies, suggest example(s) (including possible } \\
\text { activities and methods) to illustrate how they can achieve the goals for 21st century education: } \\
\text { (1) [Wiki] (Group 2) } \\
\text { (2) [Locative Technology] (Group 5) } \\
\text { (3) [Metaverse] (Group 4) } \\
\text { (4) [Social Networking](Group 3) } \\
\text { (5)[Podcasting] (Group 1) } \\
\text { Reference: } \\
\text { Social software and learning. (Section 2.2-2.7) } \\
\text { http://www.futurelab.org.uk/research/opening_education/social_software_01.htm } \\
\text { *Please create a sub-page for your group, and develop your example(s) for sharing. }\end{array}$ \\
\hline $\begin{array}{l}\text { Group } \\
\text { Presentation: } \\
\text { Impacts of } \\
\text { Internet and } \\
\text { Digital Cultures }\end{array}$ & $\begin{array}{l}\text { Referring to the following assigned web technologies, make a presentation to address the } \\
\text { questions raised here. } \\
\text { Web Technologies: } \\
\text { (1) [Wiki] (Group 2) } \\
\text { (2) [Locative Technology] (Group 5) } \\
\text { (3) [Metaverse] (Group 4) } \\
\text { (4) [Social Networking](Group 3) } \\
\text { (5) [Podcasting] (Group 1) } \\
\text { Questions: } \\
\text { What are the selected technologies? (a brief background) } \\
\text { Can you give a popular example? } \\
\text { What can we do with these technologies? (their features and functions) } \\
\text { Can you tell us any one culture or subculture that you have identified? Can you give an } \\
\text { example? } \\
\text { What sort of impact(s) do(es) your identified culture/subculture have on society or human } \\
\text { welfare? } \\
\text { What are the examples or references that help support your arguments? (examples or list of } \\
\text { references) } \\
\text { You are going to develop a database about the selected technology and your main points of } \\
\text { discussion by creating your sub-pages here or creating your own Google Sites. You are going to } \\
\text { make a short presentation about your work to your classmates (about } 20 \text { minutes) in Session } 12 .\end{array}$ \\
\hline
\end{tabular}




\section{Data collection}

To solicit the answer to the first two research questions, a questionnaire was constructed (see Table $3 \&$ 4). A total of 15 survey items with factor loadings greater than 0.7 were used for the questionnaire; the items were clustered into two main factors, perceived usefulness and attitudes, after conducting principal components analysis. The perceived usefulness subscale consisted of seven items (item1 to item7) ( $\alpha=$ 0.803 ), and the attitudes subscale consisted of eight items (item8 to item15) $(\alpha=0.851$ ). The overall Cronbach's alpha of the instrument was 0.881 . The items were rated on a 5-point Likert scale (from strongly agree to strongly disagree). At the end of the questionnaire, four open-ended questions were presented, requiring the participants to express subjective opinions on the use of wikis in learning.

The second instrument used to classify participants' learning style preferences was the ILS questionnaire, which was developed by Soloman and Felder (n.d.). The ILS questionnaire is an online instrument containing 44 dichotomous items to capture students' preferences on the four dimensions: active-reflective (ACT-REF), sensing-intuitive (SEN-INT), visual-verbal (VIS-VEB), and sequential-global (SEQ-GLO). For example, "I find it easier (a) to learn facts; (b) to learn concepts." is an item in the ILS questionnaire regarding the dimension sensing-intuitive. The ILS questionnaire was widely used in research related to e-learning systems for identifying the learning styles profile of the samples. Zywno (2003) conducted a study on the instrument and found a significantly high test-retest reliability index among the four dimensions (0.725 to 0.870 ) and a strong internal consistency reliability, with Cronbach's alpha ranging from 0.53 to 0.7 , which is acceptable for attitude assessment (Tuckman, 1999). Factor analyses were carried out, and finally, the validity of the four dimensions (constructs) proposed in the ILS questionnaire was confirmed. The original instrument adopted a bipolar scale with scores ranging from 1 to 11 in each end of the scale (a score of 1 to 3 indicates no significant preference in the pair, 5 to 7 indicates moderate preference towards a specific learning style, and 9 to 11 indicates a very strong preference towards it). To simplify the analysis, the scale in the present study was remapped into three categories (1 to 3), in which 1 implied preference (original scale from 5 to 11) to the left-hand side of the pair, 3 represented a preference (original scale from 5 to 11) to the other end, and 2 (original scale from 1 to 3 ) represented no preference towards either end of the scale.

Table 2

Percentage (no.) of participants' ILS profile $(N=39)$

\begin{tabular}{lcccc}
\hline & With preference & No preference & With preference & \\
& $(1)$ & $(2)$ & $(3)$ & \\
\hline ACT & $25.6(10)$ & $56.4(22)$ & $18.0(7)$ & REF \\
SEN & $38.5(15)$ & $56.4(22)$ & $5.1(2)$ & INT \\
VIS & $71.8(28)$ & $28.2(11)$ & $0.0(0)$ & VEB \\
SEQ & $2.6(1)$ & $84.6(33)$ & $12.8(5)$ & GLO \\
\hline
\end{tabular}

The ILS questionnaire was administered at the beginning of the first session of the PIDC course. Participants were given a link to a web page on the ILS questionnaire in Blackboard (the official learning platform of the institute). Upon their completion of this instrument, the web site automatically generated a report that showed the scores on the scales of the four dimensions. The participants were then instructed to copy these results on a hardcopy of the report for subsequent analysis. Their profile of the learning style preferences is displayed in Table 2. About $56 \%$ of the participants had no particular preference between two dimensions (active-reflective and sensing-intuitive). Furthermore, 84.6\% of the participants also showed no preference in the sequential-global dimension. However, an interesting observation is that $71.8 \%$ of these participants were visual learners, and none of them were verbal ones. To show whether there are any interaction effects among these four dimensions in the ILS questionnaire, a chi-square test was conducted, and a significant difference was only found between the dimension pair, sensing-intuitive and sequential-global $\left(\chi^{2}=10.290, \mathrm{df}=4, p<0.05\right.$ ), with a moderate association (Cramer's $\mathrm{V}=0.363, p$ $<0.05$ ). This result is similar to that of Felder and Spurlin's (2005) study. Therefore, this dimension pair may have an interaction effect that should be addressed when doing subsequent inferential testing (consequently a two-way ANOVA was conducted instead of one-way). 


\section{Analysis}

Analyses of the responses obtained from the participants were performed by using the Statistical Package for the Social Sciences. In answering research question 1, a descriptive analysis was conducted on the quantitative data from the questionnaire survey to explore student teachers' perceptions of using wikis for collaborative learning (see Tables 3 and 4). To facilitate data analysis for finding the answer to research question 2, the scores rated on a 5-point Likert scale in each of the questionnaire items of the two factors, perceived usefulness and attitudes, were summed to form a composite score for each factor. The maximum score of factor 1 was 35, whereas that of factor 2 was 40. These composite scores were then used as the dependent variables for subsequent analyses. A one-way ANOVA and a two-way ANOVA were conducted to examine the differences in the perceptions of using a wiki for collaborative learning among the student teachers with different learning style preferences (for active-reflective and visual-verbal dimensions, and sensing-intuitive and sequential-global dimensions respectively). Hence, the following null hypothesis was tested: "There is no difference in perceived usefulness of and attitudes towards using a wiki for collaborative learning among student teachers with different learning style preferences.” A Bonferroni post hoc test was performed to identify the learning style preference(s) that may be more favourable to using a wiki for collaborative learning. The answers to research question 3 were collected from the participants' feedback on the four open-ended questions of the questionnaire regarding their concerns about and thoughts on using a wiki for collaborative learning as follows:

1. Write at least three points about the merits of using Wiki for learning.

2. Write at least three points about the limitations of using Wiki for learning.

3. State the reasons for choosing the option 'Strongly disagree/Very dissatisfied' in the items in Part II to Part IV of the questionnaire.

4. Give other opinions.

A code book was developed based on either the pre-set themes or the themes distilled from the collected responses. After, feedback from the participants was coded and assigned into at least one of the defined categories in the code book. A range of subcategories was also generated based on the nature of the feedback to enable further analysis and comparison (see Tables 6 to 8 ).

\section{Results}

The results of this study are reported in accordance with the three research questions in the following sections.

\section{Perceptions of using a wiki for collaborative learning}

\section{Perceived usefulness}

Table 3 shows that the overall mean percentage of the participants who agreed or strongly agreed with all these items was $77.1 \%$, which indicates that a large proportion of the participants possessed a positive perception of the usefulness of a wiki for implementing collaborative learning. Item 4 was rated the highest. $87.5 \%$ of them agreed or strongly agreed that a wiki helps to generate content coming from shared understanding in collaborative tasks. $80.4 \%$ of them agreed or strongly agreed that a wiki facilitates the interaction between learners and instructors as well as the sharing of culture (items 3 and 5). $78.6 \%$ of them agreed or strongly agreed that a wiki facilitates collaboration in group activities. Only $67.9 \%$ of them agreed or strongly agreed that a wiki can promote interaction among group members (item 2). Finally, less than $60 \%$ of the participants agreed or strongly agreed that a wiki can facilitate self-reflection (item 6). 
Table 3

Percentage of participants' perceived usefulness of using a wiki $(N=56)$

\begin{tabular}{|c|c|c|c|c|c|}
\hline & $\begin{array}{c}\text { Strongly } \\
\text { agree }\end{array}$ & Agree & $\begin{array}{c}\text { Neutral/ } \\
\text { uncertain }\end{array}$ & Disagree & $\begin{array}{l}\text { Strongly } \\
\text { disagree }\end{array}$ \\
\hline $\begin{array}{l}\text { 1. Wiki facilitates cooperation (collaboration) } \\
\text { among group members. }\end{array}$ & 5.4 & 73.2 & 19.6 & 1.8 & 0 \\
\hline $\begin{array}{l}\text { 2. Wiki facilitates interaction (communication) } \\
\text { among group members. }\end{array}$ & 0 & 67.9 & 26.8 & 5.4 & 0 \\
\hline $\begin{array}{l}\text { 3. Wiki facilitates interaction (communication) } \\
\text { between learners and instructor. }\end{array}$ & 3.6 & 76.8 & 14.3 & 5.4 & 0 \\
\hline $\begin{array}{l}\text { 4. Wiki facilitates creation of contents of shared } \\
\text { understanding on a topic or an issue in a task } \\
\text { collaboratively. }\end{array}$ & 5.4 & 82.1 & 10.7 & 1.8 & 0 \\
\hline $\begin{array}{l}\text { 5. Wiki facilitates the promotion of sharing } \\
\text { culture. }\end{array}$ & 12.5 & 67.9 & 17.9 & 1.8 & 0 \\
\hline 6. Wiki facilitates self-reflection on learning. & 5.4 & 51.8 & 39.3 & 1.8 & 1.8 \\
\hline $\begin{array}{l}\text { 7. Wiki allows re-examination of a work and thus } \\
\text { provides a record of development in learning. }\end{array}$ & 8.9 & 78.6 & 12.5 & 0 & 0 \\
\hline
\end{tabular}

Attitudes

Table 4 shows the participants' attitudes towards using a wiki that facilitates various learning activities. The overall mean percentage of the participants who agreed or strongly agreed with all of these items was $68.3 \%$, which indicates a generally positive attitude towards the wiki activities. Item 9 rated the highest. $80.3 \%$ of the participants agreed or strongly agreed that the instructions in the wiki site help to guide learners through the collaborative tasks effectively. Around $75 \%$ of them understood the requirements and expectations of the collaborative tasks and that such tasks can enhance their understanding (items 8 and 14). About $67 \%$ of them agreed or strongly agreed that online resources help them concentrate on tackling questions or problems and that they can gain an in-depth understanding of a topic by collaborating on a wiki page (items 10 and 11). 60.7\% of them agreed or strongly agreed that they can learn from the wiki pages of other groups and that they will use a wiki in their teaching in the future (items 12 and 15). However, only $57.2 \%$ of them agreed or strongly agreed that they enjoy learning via wiki activities (item 13).

Table 4

Percentage of participants' attitudes towards Wiki activities $(N=56)$

\begin{tabular}{|c|c|c|c|c|c|}
\hline & $\begin{array}{l}\text { Strongly } \\
\text { agree }\end{array}$ & Agree & $\begin{array}{c}\text { Neutral/ } \\
\text { uncertain }\end{array}$ & Disagree & $\begin{array}{l}\text { Strongly } \\
\text { disagree }\end{array}$ \\
\hline $\begin{array}{l}\text { 8. I understand the requirements and } \\
\text { expectations of a task in a wiki activity. }\end{array}$ & 7.1 & 69.6 & 19.6 & 3.6 & 0 \\
\hline $\begin{array}{l}\text { 9. The instructions guide me through the task in a } \\
\text { wiki activity effectively. }\end{array}$ & 8.9 & 71.4 & 14.3 & 5.4 & 0 \\
\hline $\begin{array}{l}\text { 10. The links to online resources in a wiki activity } \\
\text { allow me to concentrate on tackling the } \\
\text { questions or problems in a task. }\end{array}$ & 5.4 & 62.5 & 30.4 & 1.8 & 0 \\
\hline $\begin{array}{l}\text { 11. I have in-depth understanding of a topic or an } \\
\text { issue during the creation of a wiki page } \\
\text { collaboratively. }\end{array}$ & 7.1 & 60.7 & 32.1 & 0 & 0 \\
\hline $\begin{array}{l}\text { 12. I also learn from the contents of a wiki page } \\
\text { created by other groups. }\end{array}$ & 8.9 & 51.8 & 33.9 & 3.6 & 1.8 \\
\hline 13. I enjoy learning via wiki activities. & 3.6 & 53.6 & 28.6 & 14.3 & 0 \\
\hline $\begin{array}{l}\text { 14. Wiki activities enhance my understanding of a } \\
\text { topic or an issue in this module. }\end{array}$ & 5.4 & 69.6 & 23.2 & 1.8 & 0 \\
\hline 15. I will use Wiki in my teaching in the future. & 7.1 & 53.6 & 37.5 & 1.8 & 0 \\
\hline
\end{tabular}




\section{Learning style differences}

Table 5 shows the mean composite scores of the two factors, perceived usefulness and attitudes, among participants with different learning style preferences. A one-way ANOVA was conducted to test the learning style difference between the active-reflective and visual-verbal dimensions of the ILS questionnaire with the questionnaire. The results show that a significant difference existed between the active-reflective dimension and the second factor, attitudes $\left[\mathrm{F}_{(2,36)}=3.269, p=0.05\right]$. No significant difference was found between the active and reflective learners with the first factor in this study as well as all factors between the visual and verbal learners. A Bonferroni post hoc test detected a significant mean difference between the groups that had preference for ACT $(M=31.1, S D=2.56)$ and that for REF $(M=$ $27.43, S D=4.72$ ). It shows that the active learners had a higher acceptance for using a Wiki than the reflective ones in this sample.

Table 5

Factors' mean composite scores among participants with different learning style preferences $(N=39)$

\begin{tabular}{|c|c|c|c|c|c|c|c|c|c|c|c|c|c|c|c|c|}
\hline & \multicolumn{4}{|c|}{ ACT-REF } & \multicolumn{4}{|c|}{ SEN-INT } & \multicolumn{4}{|c|}{ VIS-VEB } & \multicolumn{4}{|c|}{ SEQ-GLO } \\
\hline & Style & $\mathrm{N}$ & M & SD & Style & $\mathrm{N}$ & M & SD & Style & $\mathrm{N}$ & M & SD & Style & $\mathrm{N}$ & M & SD \\
\hline \multirow{3}{*}{$\begin{array}{l}\text { Factor } 1 \\
\text { (perceived } \\
\text { usefulness) }\end{array}$} & ACT & 10 & 27.10 & 2.18 & SEN & 15 & 26.20 & 2.39 & VIS & 11 & 26.36 & 2.73 & SEQ & 1 & 26.00 & - \\
\hline & $\mathrm{NoP}$ & 22 & 26.73 & 1.78 & NoP & 22 & 26.32 & 2.63 & NoP & 28 & 26.46 & 2.55 & NoP & 33 & 26.18 & 2.63 \\
\hline & REF & 7 & 24.57 & 4.28 & INT & 2 & 29.50 & 2.12 & VEB & 0 & - & - & GLO & 5 & 28.20 & 1.64 \\
\hline \multirow{3}{*}{$\begin{array}{l}\text { Factor } 2 \\
\text { (attitudes) }\end{array}$} & ACT & 10 & 31.10 & 2.56 & SEN & 15 & 30.27 & 1.83 & VIS & 11 & 30.21 & 2.67 & SEQ & 1 & 32.00 & - \\
\hline & NoP & 22 & 30.00 & 2.41 & NoP & 22 & 29.00 & 3.37 & NoP & 28 & 28.82 & 4.05 & NoP & 33 & 29.64 & 3.24 \\
\hline & REF & 7 & 27.43 & 4.72 & INT & 2 & 35.50 & 2.12 & VEB & 0 & - & - & GLO & 5 & 30.60 & 2.61 \\
\hline
\end{tabular}

ACT-REF = active-reflective, SEN-INT = sensing-intuitive, VIS-VEB = visual-verbal, SEQ-GLO = sequential-global, NoP = No preference, Factor 1 Max = 35; Factor $2 \mathrm{Max}=40$

The results of the two-way ANOVA reveal no interaction effect between the sensing-intuitive and sequential-global dimensions in the ILS questionnaire in the two factors of the questionnaire. Nonetheless, a significant difference was identified between the sensing-intuitive dimension and the second factor, attitudes $[\mathrm{F}(2,33)=4.632, p=0.015]$. However, a Bonferroni post hoc test only found a significant mean difference between the groups that had a preference for INT $(M=35.5, S D=2.12)$ and the groups that had no preference $(M=29.0, S D=3.37)$. No significant differences were found between the intuitive and the sensing learners or between the sequential and global learners for all factors in this study.

\section{Student teachers' concerns and thought}

Responses from the open-ended questions in the questionnaire were coded into three main categories, which were then divided into different sub-categories and themes. The total number of responses was 230.

Participants' views on the merits of using a wiki

A total of 158 responses (68.7\% of the total responses) were obtained for the Participants' views on the merits of using a wiki (merits) category. Table 4 shows that the responses were clustered into three sub-categories. More than half (57.6\%) of the responses in the category involved learning; $36.7 \%$ involved usage, and the rest (5.7\%) were about the wiki system. The two most reported themes under the learning sub-category were ML1 Allows interaction/sharing and ML2 Editable contents. An example of ML1, which is quoted directly from the response, is "Allow group members to work on the same page after class"; for ML2, an example would be "We can edit the data from time to time."

Regarding the merits in the general usage of Wiki, the number of responses in the themes for MU1 Easy to use, MU2 Efficient, MU3 Convenient and MU4 Platform to contribute resources did not differ greatly.

For the merits of the wiki system, some responses show that it has a user-friendly design and that it is a reliable tool to use. 
Table 6

Number and percentage of responses in the merits category

\begin{tabular}{llcc}
\hline Sub-category & Theme & Count & \% in category \\
\hline Learning & ML1 Allows interaction/sharing & 61 & 38.60 \\
& ML2 Editable contents & 19 & 12.03 \\
& ML3 Facilitate self-learning & 7 & 4.43 \\
& ML4 Lively learning atmosphere & 2 & 1.27 \\
& ML5 Reflect learning progress & 2 & 1.27 \\
\multirow{5}{*}{ Usage } & Sub-total & 91 & 57.60 \\
& MU1 Easy to use & 15 & 9.49 \\
& MU2 Efficient & 15 & 9.49 \\
& MU3 Convenient & 14 & 8.86 \\
& MU4 Platform to contribute resources & 11 & 6.96 \\
\multirow{5}{*}{ System } & MU5 Division of labour & 3 & 1.90 \\
& Sub-total & 58 & 36.7 \\
& MS1 User-friendly layout design & 7 & 4.43 \\
& MS2 Reliable tool & 2 & 1.27 \\
& Sub-total & 9 & 5.7 \\
\hline
\end{tabular}

Participants' views on the disadvantages of using a wiki

We obtained a total of 40 (17.39\% of the total responses) for the Participants' views on the disadvantages of using a wiki (disadvantages) category. Table 5 shows that more than half (52.5\%) of the responses in the disadvantages category involved the system's design and technical aspect, $42.5 \%$ of the responses involved learning, and 5\% discussed general usage. The most reported theme about learning was DL1 Unprofessional/false information; an example of a typical response of this type is "False information may be shared and not corrected at all." Only 2 responses were obtained for the usage sub-category; both of the respondents expressed that they could not immediately interact with others face-to-face in the class. The two most reported themes in the system sub-category were DS1 Technical problems and DS2 Lack of concurrent editing.

Table 7

Number and percentage of responses in the disadvantages category

\begin{tabular}{llcc}
\hline Sub-category & Theme & Count & \% in category \\
\hline Learning & DL1 Unprofessional/false information & 8 & 20.00 \\
& DL2 Lack of immediate face-to-face interaction & 7 & 17.50 \\
& DL3 Unknown/unreliable source of information & 4 & 10.00 \\
& Sub-total & 19 & 47.50 \\
System & 6 & 15.00 \\
& DS1 Technical problems & 5 & 12.50 \\
& DS2 Lack of concurrent editing & 2 & 5.00 \\
& DS3 Dull design & 2 & 5.00 \\
& DS4 Confusing instruction & 2 & 5.00 \\
& DS5 Limited size of file uploads & 2 & 5.00 \\
& DS6 Inconvenient photo import & 1 & 2.50 \\
& DS7 Limited functionality & 1 & 2.50 \\
& DS8 Long loading time & 21 & 52.5 \\
\hline Sub-total & 40 & 100.00 \\
\hline
\end{tabular}

\section{Other concerns}

$13.91 \%$ of the total responses (32 responses) were in the other concerns category. According to Table 6, O1 Lack of experience in using a wiki was the most common theme (25.00\%) found in this category. The 
second most reported concern was O2 Need extra effort on the design of lesson plan (21.88\%). O3 Distractions from other links and applications and $\mathrm{O} 4$ Ensure students' participation were also concerns of some student teachers about using a wiki platform.

Table 8

Number and percentage of responses in the other concerns category

\begin{tabular}{lcc}
\hline Theme & Count & \% in category \\
\hline O1 Lack of experience in using Wiki & 8 & 25.00 \\
O2 Need extra effort on the design of lesson plan & 7 & 21.88 \\
O3 Distractions from other links and applications & 4 & 12.50 \\
O4 Ensure students' participation & 4 & 12.50 \\
O5 Required to check the updates frequently & 3 & 9.38 \\
O6 Progress affected by others & 2 & 6.25 \\
O7 Plagiarism & 2 & 6.25 \\
O8 Affecting eyesight & 1 & 3.13 \\
O9 Classroom management skills & 1 & 3.13 \\
\hline Total & 32 & 100.00 \\
\hline
\end{tabular}

\section{Discussion and conclusion}

The results above show that the student teachers who participated in this study viewed the value of using a wiki as positive. The majority of them agreed that a wiki facilitates collaboration and interaction, which might contribute to the understanding of a topic and the development of thinking skills as well as enabling positive social reactions (Wells \& Chang-Wells, 1992).

Furthermore, when the student teachers were asked about their attitudes towards different collaborative activities with the use of a wiki (see Table 1), most of them gave positive responses, which implied that they generally accepted the idea of integrating a wiki into teaching and learning. These positive findings may be due to the user-friendliness and the clear structure of the wiki platform. Results from the open-ended questions show some supporting evidence, where "convenient" and "easy to use" were common responses in the 'merit' sub-category. Similar findings were observed in Huang, Yoo, and Choi's (2008) study, wherein wiki was rated the highest among various Web 2.0 technologies in enhancing learning.

Although $77.1 \%$ of the participants agreed or strongly agreed with the items related to perceived usefulness in the questionnaire, only $57.2 \%$ of the participants agreed or strongly agreed with the statement "Wiki facilitates self-reflection on learning" (item 6), which is comparatively lower than the percentages of items 1 to 5 , which describe the collaborative type of learning. This result implies that the participants' perceived usefulness of using Wiki in individual reflection is lower than that in collaborative learning.

The results of the inferential analysis in this study show that active learners had a higher intention of using wikis than the reflective learners. According to Felder and Silverman (1988), active learners do not like listening and watching passively in a class. They prefer to work in groups and on tasks which require discussing, questioning, arguing, brainstorming, experimenting or reflecting. Given these characteristics, it is obvious that a wiki is a proper platform for active learners as it supports online collaborative activities that match well with their learning style (Table 1). However, only $25.6 \%$ (Table 2) of the student teachers in this sample are active learners. It leaves room for further study for deriving effective pedagogies that suit students with other learning styles, for example, visual, which is the majority $71.8 \%$ (Table 2) in this study.

Although this study did not find a significant mean difference in any factor between the sensing and intuitive groups due to the small sample, intuitive learners achieved the highest mean composite score in this SEN-INT dimension. A similar result was found in the study conducted by Beadles and Lowery (2007) in which the ILS questionnaire was also used. It shows that intuitive learners significantly prefer 
web-based learning activities more than those with other learning styles. Felder and Silverman (1988) described an intuitive learner as one who likes innovative and complicated tasks and prefers to learn from principles and theories. These are the most expected characteristics in many professions like engineer and teacher. Unfortunately, the number of student teachers with such learning style in this study was very small (5.1\%, Table 2). It leads to two very interesting research questions to be addressed in the future studies:

- Will the learning style profile identified in this sample represent that in a teacher education institute or even the teacher profession?

- What is/are the most popular learning style(s) that can be found in a teacher education institute or the teacher profession?

The answers to these two questions may help to develop particular teaching strategies that address the learning style issue in the teaching profession as well as to draw up policies and measures that can attract intuitive learners to join this profession.

Reponses collected from the open-ended questions provide us with some insight regarding the student teachers' concerns when implementing wikis into teaching and learning. The majority of the responses were in the merits category, implying that participants generally had a good understanding of the wiki's advantages and that they might be willing to use it in teaching in the future.

While a number of the student teachers expressed the view that the wiki is an effective tool for sharing and interactive activities (Table 6), some also reported that it possesses a lack of direct interaction between users (Table 7). Student teachers seem to treasure face-to-face interaction, consider it as an essential element in teaching and learning, and understand that technology will not replace traditional classroom interaction, which involves the use of gestures, eye contact, and physical interactions.

Editable contents was commented as a good feature of a wiki (Table 6). However, Lack of concurrent editing, on the contrary, was criticised as one of the most reported disadvantages in this study (Table 7). Today, contents on a wiki page can only be edited by one person at a time, whereas some online tools such as Google Docs allow 50 people to edit a document simultaneously. This is clearly a major limitation of the system, as real-time collaborative work thus becomes impossible. However, the result also reflects that the culture of after-class asynchronous collaboration still lacks development. A greater effort should be exerted in this area, such as assigning more after-class collaborative tasks.

Technical problems (Table 7), Lack of experience in using Wiki (Table 8) and Need extra effort on the design of lesson plan (Table 8) were also often reported themes among the responses. The occurrence of such implies that some of the respondents might not have sufficient knowledge for effectively using Wiki as a teaching or learning tool. Therefore, future users of the system must ensure that enough training and technical support are provided when implementing the use of Wiki in collaborative learning activities. Hence, learners' self-efficacy in a particular technology remains a major external factor for successful implementation of pedagogy, as stated by Teo (2011).

The majority of the responses in the disadvantage category were in the system sub-category, implying that the usability and functionality of a wiki received the most criticism. This could be the result of the problematic design or the technical limitations of the system. It may also be a result of the discrepancy between the respondents' expectations and the actual performance of the system due to the lack of sufficient training on its use. Hence, in addition to users' competence, the characteristic of a system is also an often neglected factor that affects the proper use of a technology in pedagogy, as stated by Davis (1993).

Despite rather positive results, apparent limitations of this study can be observed as well. First, the student teachers were chosen via convenience sampling. Their characteristics, for example, the learning styles profile as displayed in Table 2, might not be an accurate representation of all the student teachers in the institute. Hence, the results obtained in this study cannot be generalised or applied in other contexts and might only be applicable to this sample or to other samples with similar characteristics. Moreover, representative samples of each learning style preference could not be used because the sample size of this study was small. Therefore, larger samples and a stratified sampling method should be adopted in future 
studies. Second, potential bias may be a problem because the researcher also acted as the instructor of the course in this study. Hence, particular attention was paid to the handling of the research data and assessment materials for the course. The participants were assured that their responses and the creation of learning style profiles did not contribute in any form towards assessment in the course. The researcher also strived to maintain a relaxed and non-hierarchical relationship with the participants and to conduct the lessons in a natural manner.

More in-depth follow-up studies are needed to enrich the findings of this study. For instance, interviews may be conducted to reveal the underlying reasons for the items having only fairly favourable responses (e.g., items 6 and 13 in the questionnaire) and to analyse the time that participants had spent in different collaborative activities when using the wiki platform. To solicit the effect of this intervention on learning outcomes, discourse analyses on the qualitative data of participants' performance in the collaborative activities logged in the wiki web site may be studied. Apart from the perceptions of the students and the collaborative nature of the wiki platform, other external factors such as the learners' and system characteristics can affect the acceptance of a technology as reviewed in this study. Other influences may exist, such as the influence of peers as stated by Venkatesh and Davis (2000). Hence, in-depth investigations to identify possible influences on the effective use of Wikis remain an important agenda in future studies. The findings in this study also address issues related to the need for sufficient training and good design such as the navigation, interface, and functionality of a system when a similar intervention is attempted.

\section{References}

Asterhan, C., \& Schwarz, B. (2010). Online moderation of synchronous e-argumentation. International Journal of Computer-Supported Collaborative Learning, 5(3), 259-282. doi:10.1007/s11412-010-9088-2

Augar, N., Raitman, R., \& Zhou, W. (2004). Teaching and learning online with wikis. In Atkinson, R., McBeath, C., Jonas-Dwyer, D. \& Phillips, R. (Eds). Proceedings of the 21st ASCILITE Conference (pp. 95-104). Retrieved from http://www.ascilite.org.au/conferences/perth04/procs/pdf/augar.pdf

Beadles, N., \& Lowery, C. (2004). An exploratory analysis of the learning styles of students in an on-line degree program. Communications of the IIMA, 4(1), 17-24.

Beadles, N., \& Lowery, C. (2007). Self-selection into degree programs: Differences in preferred learning styles between online students and traditional students. Academy of Educational Leadership Journal, 11(2), 103-112.

Bonk, C. J., \& Cunningham, D. J. (1998). Searching for learner-centred, constructivist, and socialcultural components of collaborative learning tools. In C. J. Bonk, D. J. Cunningham, \& K. S. King (Eds.), Electronic collaborators: Learner-centred technologies for literacy, apprenticeship, and discourse (pp. 25-50). Mahwah, NJ: Erlbaum.

Bruffee, K. A. (1995). Sharing our toys: Cooperative learning versus collaborative learning. Change, 27(1), 12-18. doi:10.1080/00091383.1995.9937722

Bruner, J. (1966). Toward a theory of instruction. Cambridge. MA: Harvard University Press.

Choi, H. S., Park, J. W., \& Park, S. B. (2012). A study on the effect of mobile tourism information services on tourist satisfaction and continual reuse intention. International Journal of Business and Information Technology, 1(3), 189-195.

Coffield, F., Moseley, D., Hall, E., \& Ecclestone, K. (2004). Should we be using learning styles? What research has to say to practice. London: Learning and Skills Development Agency. Retrieved from http://itslifejimbutnotasweknowit.org.uk/files/LSRC_LearningStyles.pdf

Cohen, E. (1994). Designing groupwork: Strategies for the heterogeneous classroom (2nd ed.). New York, NY: Teachers College Press.

Davis, F. D. (1989). Perceived usefulness, perceived ease of use, and user acceptance of information technology. MIS Quarterly, 13(3), 319-340.

Davis, F. D. (1993). User acceptance of information technology: System characteristics, user perceptions and behavioral impacts. International Journal of Man-Machine Studies, 38, 475-487. doi:10.1006/imms.1993.1022

Dede, C. (2005). Planning for neomillennial learning styles: Implications for investments in technology and faculty. In D. G. Oblinger \& J. L. Oblinger (Eds.), Educating the net generation (pp. 15.1-15.22). Louisville, CO: EDUCAUSE. Retrieved from 
http://www.educause.edu/research-and-publications/books/educating-net-generation

Doolittle, P. E., \& Hicks, D. (2003). Constructivism as a theoretical foundation for the use of technology in social studies. Theory \& Research in Social Education, 31(1), 72-104. doi:10.1080/00933104.2003.10473216

Driscoll, M. (2000). Psychology of learning for instruction. Needham Heights, MA: Allyn \& Bacon.

Dunn, R., \& Dunn, K. (1993.) Teaching secondary students through their individual learning styles: Practical approaches for grade 7-12. Boston, MA: Allyn \& Bacon.

Duren, P. E., \& Cherrington, A. (1992). The effects of cooperative group work versus independent practice on the teaching of some problem solving strategies. School Science and Mathematics, 92(2), 80-83. doi:10.1111/j.1949-8594.1992.tb12146.x

EDUCAUSE. (2005). “7 things you should know about ... wikis”. Retrieved from http://www.educause.edu/ir/library/pdf/ELI7004.pdf

Engstrom, M. E., \& Jewett, D. (2005). Collaborative learning: The wiki way. TechTrends, 49(6), 12-15. doi:10.1007/BF02763725

Felder, R. M. (1993). Reaching the second tier: Learning and teaching styles in college science education. Journal of College Science Teaching, 23(5), 286-290.

Felder, R. M., \& Brent, R. (2005). Understanding student differences. Journal of Engineering Education, 94(1), 57-72. doi:10.1002/j.2168-9830.2005.tb00829.x

Felder, R. M., \& Silverman, L. K. (1988). Learning and teaching styles in engineering education. Engineering Education, 78(7), 674-681.

Felder, R. M., \& Soloman, B. A. (n.d.). Index of learning styles (ILS) Retrieved from http://www4.ncsu.edu/unity/lockers/users/f/felder/public/ILSpage.html

Felder, R. M., \& Spurlin, J. (2005). Applications, reliability and validity of the index of learning styles. Journal of Engineering Education, 21(1), 103-112.

Goodnoe, E. (2005). Wikis make collaboration easier. InformationWeek, 1053, 54-58.

Harasim, L. M., Hiltz, S.R., Teles, L., \& Turoff, M. (1995). Learning networks: A field guide to teaching and learning online. Cambridge, MA: MIT Press.

Hattie, J. (2009). Visible learning; A synthesis of over 800 meta-analyses relating to achievement. London: Routledge.

Hewitt, J. (2002). From a focus on tasks to a focus on understanding: The cultural transformation of a Toronto classroom. In T. Koschmann, R. Hall, \& N. Miyake. (Eds.), Computer supported cooperative learning volume 2: Carrying forward the conversation (pp. 11-41). Mahwah, NJ: Erbaum.

Hoppe, H., Ogata, H., \& Soller, A. (Eds.). (2007). The role of technology in CSCL: Studies in technology enhanced collaborative learning. New York, NY: Springer. doi:10.1007/978-0-387-71136-2

Huang, W. D., Yoo, S. J., \& Choi, J. H. (2008). Correlating college students' learning styles and how they use Web 2.0 applications for learning. In C. Bonk, M. M. Lee, \& T. Reynolds (Eds.), Proceedings of World Conference on E-Learning in Corporate, Government, Healthcare, and Higher Education 2008 (pp. 2752-2759). Chesapeake, VA: AACE.

Jensen, G. H. (2003). Learning styles. In J. A. Provost \& W. S. Anchors (Eds.), Using the MBTI instrument in colleges and universities (pp. 123-155). Gainesville, FL: Center for Applications of Psychological Type.

Johnson, D. W., \& Johnson, R. T. (1989). Cooperation and competition: Theory and research. Edina, MA: Interaction Book Company.

Jonassen, D. H. (1994). Thinking technology: Toward a constructivist design model. Educational Technology, 34(4), 35-36. doi:10.1080/08923649509526885

Jonassen, D. H., Davidson, M., Collins, M., Campbell, J., \& Haag, B. B. (1995). Constructivism and computer-mediated communication in distance education. American Journal of Distance Education, 9(2), 7-25.

Keefe, J. W. (1979). Learning style: An overview. In Student learning styles: Diagnosing and prescribing programs (pp. 1-17). Reston, VA: National Association of Secondary School Principals.

Kimmerle, J., Moskaliuk, J., \& Cress, U. (2009). Learning and knowledge building with social software. In C. O’Malley, D. Suthers, P. Reimann, \& A. Dimitracopoulou (Eds.), Proceedings of the 2009 Conference for Computer Supported Collaborative Learning Practices (Vol. 1, pp. 459-468). International Society of the Learning Sciences.

Kirschner, P. A., Martens, R. L., \& Strijbos, J. W. (2004). CSCL in higher education? A framework for designing multiple collaborative environments. In J. W. Strijbos, P. A. Kirschner, \& R. L. Martens 
(Eds.), What we know about CSCL: And implementing it in higher education (pp. 3-30). Boston, MA: Kluwer. doi:10.1007/1-4020-7921-4_1

Kolb, D. (1984). Experiential learning: Experience as the source of learning and development. Englewood Cliffs, NJ: Prentice Hall.

Koschmann, T. (Ed.). (1996). CSCL: Theory and practice of an emerging paradigm. Mahwah, NJ: Erlbaum.

Koschmann, T., Hall, R., \& Miyake, N. (Eds.). (2002). CSCL 2: Carrying forward the conversation. Mahwah, NJ: Erlbaum.

Larusson, J., \& Alterman, R. (2009). Wikis to support the 'collaborative' part of collaborative learning. International Journal of Computer-Supported Collaborative Learning, 4(4), 371-402. doi:10.1007/s11412-009-9076-6

Liegle, J., \& Janicki, T. (2006). The effect of learning styles on the navigation needs of web-based learners. Computers in Human Behavior, 22(5), 885-898. doi:10.1016/j.chb.2004.03.024

Lipponen, L. (2002). Exploring foundations for computer-supported collaborative learning. In G. Stahl (Eds.), Computer Support for Collaborative Learning: Foundations for a CSCL community (pp. 72-81). Hillsdale, NJ: Erlbaum. doi:10.3115/1658616.1658627

Lu, J., Lajoie, S., \& Wiseman, J. (2010). Scaffolding problem-based learning with CSCL tools. International Journal of Computer-Supported Collaborative Learning, 5(3), 283-98. doi:10.1007/s11412-010-9092-6

Mattison, D. (2003). Quickiwiki, Swiki, Twiki, Zwiki and the Plone wars: Wiki as a PIM and collaborative content tool. Searcher, 11(4), 32-48.

Onrubia, J., \& Engel, A. (2009). Strategies for collaborative writing and phases of knowledge construction in CSCL environments. Computers \& Education, 53(4), 1256-1265. doi:10.1016/j.compedu.2009.06.008

Palincsar, A. S. (1998). Social constructivist perspectives on teaching and learning. Annual Review of Psychology, 49, 345-375. doi:10.1146/annurev.psych.49.1.345

Parker, K. R., \& Chao, J. T. (2007). Wiki as a teaching tool, Interdisciplinary Journal of Knowledge and Learning Objects, 3, 57-72.

Pituch, K. A., \& Lee, Y.-K. (2006). The influence of system characteristics on e-learning use. Computers \& Education, 47, 222-244. doi:10.1016/j.compedu.2004.10.007

Pontecorvo, C. (1993). Social interaction in the acquisition of knowledge. Educational Psychology Review, 5(3), 293-310. doi:10.1007/BF01323049

Rysavy, D. M., \& Sales, G. C. (1991). Cooperation in computer based instruction. Educational Technology Research and Development, 39(2), 70-79. doi:10.1007/BF02298155

Salomon, G., \& Perkins, D. (1998). Individual and social aspects of learning. Review of Research in Education, 23, 1-24. doi:10.2307/1167286

Scardamalia, M., Bereiter, C., \& Lamon, M. (1994). The CSILE project: Trying to bring the classroom into world 3. In K. McGilly (Ed.), Classroom lessons: Integrating cognitive theory \& classroom practice (pp. 201-228). Cambridge, MA: MIT Press.

Slavin, R. E. (1995). Cooperative learning: Theory, research, and practice (2nd ed.). Boston, MA: Allyn \& Bacon.

Soloman, B. A., \& Felder, R. M. (n.d.). Index of learning styles questionnaire. Retrieved from http://www.engr.ncsu.edu/learningstyles/ilsweb.html

Stahl, G., Koschmann, T., \& Suthers, D. (2006). Computer-supported collaborative learning: An historical perspective. In R. K. Sawyer (Ed.), Cambridge handbook of the learning sciences (pp. 409-426). Cambridge: Cambridge University Press.

Steffe, L. P., \& Gale, J. (Eds.). (1995). Constructivism in education. Hillsdale, NJ: Erlbaum.

Teo, T. (2011). Influence of user characteristics on teachers' intention to use technology. International Journal of Instructional Media, 38(2), 115-124.

Thomson, B. S., \& Diem, J. J. (1994). Fruit bats, cats, and naked mole rats: Lifelong learning at the zoo. ERIC/CSMEE Digest, ED 372 966. Retrieved from http://eric.ed.gov/?id=ED372966

Tuckman, B. W. (1999). Conducting educational research (5th ed.). Fort Worth, TX: Harcourt Brace College Publishers.

Venkatesh, V., \& Davis, F. D. (2000). A theoretical extension of the technology acceptance model: Four longitudinal field studies. Management Science, 46, 186-204. doi:10.1287/mnsc.46.2.186.11926 
Vrasidas, C. (2000). Constructivism versus objectivism: Implications for interaction, course design, and evaluation in distance education. International Journal of Educational Telecommunications, 6(4), 339-362.

Vygotsky, L. S. (1978). Mind in society: The development of higher psychological processes. Cambridge, MA: Harvard University Press.

Vygotsky, L. S. (1987). Thinking and speech. In R. Rieber \& A. Carton (Eds.), N. Minick (Trans.), The collected works of L .S. Vygotsky (pp. 39-285). Now York, NY: Plenum.

Warschauer, M. (1997). Computer-mediated collaborative learning: Theory and practice. Modern Language Journal, 81, 470-481. doi:10.1111/j.1540-4781.1997.tb05514x

Wells, G., \& Chang-Wells, G. L. (1992). Constructing knowledge together. Portsmouth, NH: Heinemann.

Woo, Y., \& Reeves, T. C. (2007). Meaningful interaction in Web-based learning: A social constructivist interpretations. Internet and Higher Education, 10, 15-25. doi:10.1016/j.iheduc.2006.10.005

Zywno, M. S. (2002). Instructional technology, learning styles and academic achievement. In Proceedings of the 2002 American Society for Engineering Education Annual Conference \& Exposition. Washington, DC: American Society for Engineering Education.

Zywno, M. S. (2003). A contribution to validation of score meaning for Felder-Soloman's index of learning styles. In T. Nashville (Ed.). Proceedings of the 2003 American Society for Engineering Education Annual Conference \& Exposition. American Society for Engineering Education. Retrieved from http://www4.ncsu.edu/unity/lockers/users/f/felder/public/ILSdir/Zywno_Validation_Study.pdf

Corresponding author: Kai Ming Li, kmli@ied.edu.hk

Australasian Journal of Educational Technology (C) 2015.

Please cite as: Li, K. (2015). Learning styles and perceptions of student teachers of computer-supported collaborative learning strategy using wikis. Australasian Journal of Educational Technology, 31(1), 32-50. 